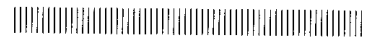

$\sum_{\|\|\|\| \||||||||||||||||||||||||||||||||||||||||||||||| \mid}$

\section{ファジイクラスタリングによる \\ 局所的マイナ一成分の抽出と欠測值の推定 ${ }^{\dagger}$}

\section{呉 志賢*1 本多 克宏*2 市橋 秀友*2}

\begin{abstract}
本研究では，ファジィクラスタリングを用いた，局所的マイナー成分の二ューラルネットアプローチによる 抽出法を提案する。さらに，抽出されたマイナー成分を用いて，デー夕集合における久測值の推定を行う方法 も同時に提案する。众测值の推定は，マイナー成分べクトルを法線とする超平面を求めて，データ点を超平面 に射影することで行う。提案法は，データの部分構造を考虑した簡便な久測值の推定法である。
\end{abstract} キーワード：マイナー成分, ファジィクラスタリング, ニューラルネットアプローチ, 久測做の推定

\section{1. はじめに}

標準的な主成分分析 (Principal Component Analy$\operatorname{sis}(\mathrm{PCA}))$ は, 変量の分散共分散行列の固有值計算か ら主成分を求めるが, Oja らによって, へブ学畾を行う ニューラルネットアプローチ［1]［2]も提案されてい る. 本研究では, ニューラルネットワークによってマ イナー成分を抽出するアルゴリズムを，ファジィクラ スタリング [3]に応用し，ファジィクラスターから四 1のような,デー夕の部分構造を考虑した隔所的マイ

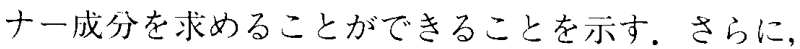
局所的マイナー成分を用いた，久测值の推定法を提案 する。

欠測值の含まれることが多い実デー夕の前処理など， データ解析において欠測值の推定は重要な役割を担っ ている．欠測值の推定方法としては，一般的に回帰分 析が朋いられている。しかし，回帰分析では目的変数 ごとに回帰を行う必要がある。また，最小2乗基準に基 づくFCV 法を用いた久測值の推定法 [4] は, データ 行列の低階数近似行列を求める解析的な方法であり, 計算アルゴリズムが複雑である。ここでは，ニューラ ルネットの学習によって求めた局所的マイナー成分を

$\dagger$ Extraction of Local Minor Component by Fuzzy Clustering and Missing Value Estimation

Chi-Hyon OH, Katsuhiro HONDA, Hidetomo ICHIHASHI

* 1 大阪経済法科大学: 教養部

Faculty of Liberal Arts and Sciences Osaka University of Economics and Law

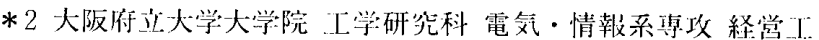
学:分野

Graduate School of Engineering,

Electrical Engineering and Information Science, Industrial Engineering, Osaka Prefecture University
用いた，簡便な欠測值の推定法を提案する。

\section{2. 局所的マイナー成分の抽出}

Bezdek らによって提案された Fuzzy c-Varieties $(\mathrm{FCV})$ 法 [5] は，データ $\boldsymbol{x}_{i}$ とべクトル $\boldsymbol{w}_{c k}$ が張る線 形多様体状のプロトタイプとの距離の総和を，最小に することでクラスターを形成する。ただし，

$$
\begin{aligned}
& \boldsymbol{x}_{i}=\left(x_{i 1}, \cdots, x_{i K}\right)^{\top}, \quad i=1, \cdots, N \\
& \boldsymbol{w}_{c k}=\left(w_{c k 1}, \cdots, w_{c k K}\right)^{\top}, \\
& \quad c=1, \cdots, C, k=1, \cdots, K-m
\end{aligned}
$$

である.ここで， $N$ はデータの個数で，Cはクラスタ 一の数である。また， $K$ はデ一夕の次元， $m$ はマイナ 一成分ベクトルの数とする。ベクトル $\boldsymbol{w}_{c k}$ を主成分べク トルとみなすと, FCV 法はファジィクラスタリングと 主成分分析の同時分析法々考えることができる。

ここで，マイナ一成分を考えると，FCV 法のクラス タリング基準は，以下のように表わすことができる。

Local minor component vector

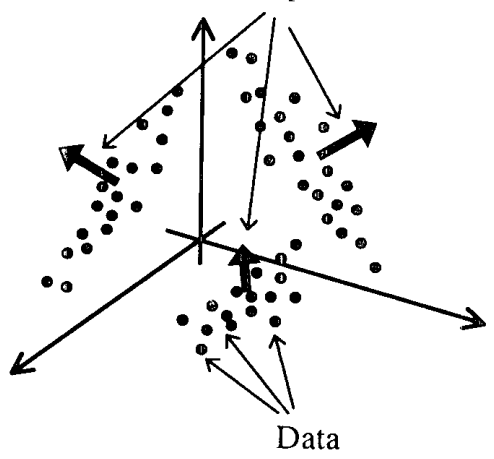

図 1：局所的マイナ一成分の抽出 


$$
\sum_{c=1}^{C} \sum_{i=1}^{N} \sum_{k=K-m+1}^{K} u_{c i} \boldsymbol{w}_{c k}^{\top}\left(\boldsymbol{x}_{i}-\boldsymbol{v}_{c}\right)\left(\boldsymbol{x}_{i}-\boldsymbol{v}_{c}\right)^{\top} \boldsymbol{w}_{c k}
$$

式(3)のベクトル $\boldsymbol{w}_{c k}$ は，マイナー成分を表す。また, $u_{c i}$ はデータのクラスタ一への帰属の度合いを表すメン バシップで， $v_{c}$ はクラスターの中心（平均）である.

式(3)の最適化は, ラグランジュの未定乗数法により, 以下の目的関数 $L$ の最小化問題に帰着させることがで きる。

$$
\begin{aligned}
L & =\sum_{c=1}^{c} \sum_{i=1}^{N} \sum_{k=K-m+1}^{K} u_{c i} \times \\
& +T_{0} \sum_{c=1}^{c} \sum_{i=1}^{N} u_{c i}^{\top} \log u_{c i} \\
& +\sum_{i=1}^{N} T_{i}\left(\sum_{c=1}^{c} u_{c i}-1\right)\left(\boldsymbol{x}_{i}-\boldsymbol{v}_{c}\right)^{\top} \boldsymbol{w}_{c k}
\end{aligned}
$$

式(4)の第 1 項目は, FCV 法のクラスタリング基準であ り，第 2 項目はエントロピー最大化による正則化を表 す. $T_{0}>0$ はファジィ度を調整するパラメータであり， $T_{0}$ の値が大きいほどあいまいなクラスターを得る。第 3 項目は，全てのクラスターに対するメンバシップの 総和が1であるという制約条件を表す. $T_{i}$ はラグランジ ュ乗数である.

$L$ を最小にする $\boldsymbol{v}_{c}, \boldsymbol{u}_{i}$ は， $L$ の最適性の必要条件よ り導出される不動点反復アルゴリズムによって求める. 最適性の必要条件 $\partial L / \partial v_{c k}=0$ より,

$$
v_{c k}=\sum_{i=1}^{N} u_{c i} x_{i k} / \sum_{i=1}^{N} u_{c i}
$$

を得る。また， $\partial L / \partial u_{c i}=0$ より，

$$
u_{c i}=\exp \left(A_{c i}\right) / \sum_{c=1}^{c} \exp \left(A_{l i}\right)
$$

ただし，

$$
\begin{aligned}
& A_{l i}= \\
& \quad-\frac{1}{T_{0}} \sum_{k=K-m+1}^{K} \boldsymbol{w}_{l k}^{\top}\left(\boldsymbol{x}_{i}-\boldsymbol{v}_{c}\right)\left(\boldsymbol{x}_{i}-\boldsymbol{v}_{c}\right)^{\top} \boldsymbol{w}_{l k}
\end{aligned}
$$

マイナー成分ベクトル $\boldsymbol{w}_{c k}$ は, Ojaのニューラルネッ トアプローチにメンバシップを考慮して求める.まず, $\partial L / \partial \boldsymbol{w}_{c k} よ り$

$$
\frac{\partial L}{\partial \boldsymbol{w}_{c k}}=2 \sum_{i=1}^{N} u_{c i}\left(\boldsymbol{x}_{i}-\boldsymbol{v}_{c}\right)\left(\boldsymbol{x}_{i}-\boldsymbol{v}_{c}\right)^{\top} \boldsymbol{w}_{c k}
$$

を得る.上記の式に基準化と直交化を加味することで, 局所的マイナー成分べクトルの更新則は以下のように なる.

$$
\begin{aligned}
& \Delta \boldsymbol{w}_{c k}=\gamma u_{c i}\left\{-y_{c k}\left(\boldsymbol{x}_{i}-\boldsymbol{v}_{c}\right)\right. \\
& +\left(y_{c k}^{2}+1-\left(\boldsymbol{w}_{c k}^{o l d}\right)^{\top} \boldsymbol{w}_{c k}^{o l d}\right) \boldsymbol{w}_{c k}^{o l d} \\
& \left.-\alpha \sum_{l>k} y_{c l} y_{c k} \boldsymbol{w}_{c l}^{o l d}\right\} \\
& \text { ここで, } \\
& y_{c k}=\left(\boldsymbol{x}_{i}-\boldsymbol{v}_{c}\right)^{\top} \boldsymbol{w}_{c k}^{\text {old }}
\end{aligned}
$$

である、また， $\gamma$ は学習率であり， $\alpha$ は正の係数で,十 分大きければ，求まるべクトルが互いに直交する.

提案アルゴリズムを以下に示す。

\section{局所的マイナー成分ベクトルの抽出アルゴリズム}

Step 1: $C, T_{0}, \gamma, \alpha, \xi, \varepsilon$ を定める.メンバシッ プ $\boldsymbol{u}_{i}$, およびマイナ一成分べクトル $\boldsymbol{w}_{c k}$ の初期 值を乱数により定める。

Step 2: 式(5)よりクラスター中心 $\boldsymbol{v}_{c}$ を求める.

Step 3: 式(9)の更新則を用いて, $\max c, k \mid \boldsymbol{w}_{c k}^{n e w}-$ $\boldsymbol{w}_{c k}^{\text {old }} \mid<\xi$ を満なすまで, マイナ一成分べクト ル $\boldsymbol{w}_{c k}$ の学習を行う。

Step 4: 式(6)よりメンバシップ $\boldsymbol{u}_{i}$ を求める.

Step 5: 収束判定条件 $\max _{c, i}\left|u_{c i}^{N E W}-u_{c i}^{O L D}\right|<\epsilon$ を満た せば終了。その他はStep 2 八戻る。

\section{3. 局所的マイナー成分を用いた 欠測値の推定}

前節のアルゴリズムによって抽出された，局所的マ イナ一成分ベクトルを用いる久测值の推定法を提案す る。データに久测值がある場合，欠測した属性を無視 して局所的マイナ一成分べクトルの抽出を行う。そし て, 久測したデータがマイナ一成分ベクトル $\boldsymbol{w}_{c K}$ を法線 とする超平面上に存在すると仮定する。すなおち，デ 一夕を $K-1$ 次元の主成分べクトルの張る超平面上に 射影し，欠測した属性を推定する。この際，データが ファジィクラスターによって分割されているので, ど の超平面に射影するかを決定しなければならない。そ こで，最大のメンバシップを持つクラスタ一の超平面 に射影する，最大值ルールを採用する。

いま，デー夕 $\boldsymbol{x}_{i}$ において，属性 $x_{i}$ が欠測していると する.属性 $l$ を推定するために, マイナ一成分べクトル $\boldsymbol{w}_{C K}$ を法線べクトルとする $K-1$ 次元の超平面を表す 線形関数は,

$$
\left(\boldsymbol{x}_{i}-\boldsymbol{v}_{c}\right)^{T} \boldsymbol{w}_{c k}=0
$$

と表される。属性 $x_{i l}$ がこの超平面上に存在すると仮定 すると, 式(11)より， 


$$
x_{i l}=-\frac{1}{w_{c l}} \sum_{m=1, m \neq l}^{M}\left(x_{i m}-v_{c m}\right) w_{c m}+v_{c l}
$$

と表すことができる。

2つの属性が久測している場合は，以下のような, 第 2 マイナ一成分ベクトル $\boldsymbol{w}_{C K-1}$ を法線とする超平面を 考える.

$$
\left(\boldsymbol{x}_{i}-\boldsymbol{v}_{c}\right)^{T} \boldsymbol{w}_{c K-1}=0
$$

式(11)と式(13)の超平面からなる連立方程式を解くこ とにより，2つの属性が久測している場合の推定を行 うことができる，久测值が 3 属性以上の場合も，欠測 した属性の数だけマイナー成分べクトルを求めれば, 久測值を推定することができる。

\section{4. 数値実験}

人工的に生成した 3 次元データを用いて，提案法に よる久測值の推定を行った。罒2 に，生成したデー夕 を示す。デー夕点の数は20である。罒 2 上り，データ は2つの部分構造を有することがわかる。数值実験で は, 図2のデー夕のうち，2つのデー夕点の属性を 1 つ久测させ，ある 1 つのデー夕点に関しては，2つの 属性を久測させて久测值の推定を行った策験で用いた パラメータは,クラスター数：C:2, エントロピー項 の係数 $T_{0}: 0.2$, ヘブ学羽習の学㖬率 $\gamma: 0.000001$, 直交 化係数 $\alpha: 10$, へブ学習の収束判定条件 $\xi: 0.000001$, 不動点反復法の収束判定条件 $\varepsilon: 0.001$ である。

提案法を朋いた欠測值の推定結果を，罒 3 ，四 4 に 示古。図 3 , 図 4 は，それぞれ3 次元デ一夕の $x_{1}-x_{2}$ 平 面, $x_{2}-x_{3}$ 平面の 2 次元プロット四である。㸚中の $\triangle$ は クラスターの中心 $v_{c}$ 表し，○とのは，それぞれ翼な るクラスターに属するデータ点を表す。デー夕点は, 最大のメンバシップを持つクラスターに属するとした。 図における×は，3件の久測值を持つデー夕点(Data 1-3)を表している，点線で結ばれたデ一夕点は，提案

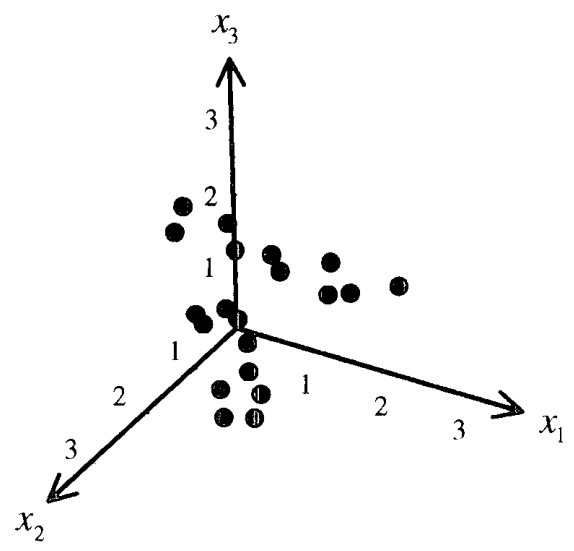

図 $2: 3$ 次元人士デー夕

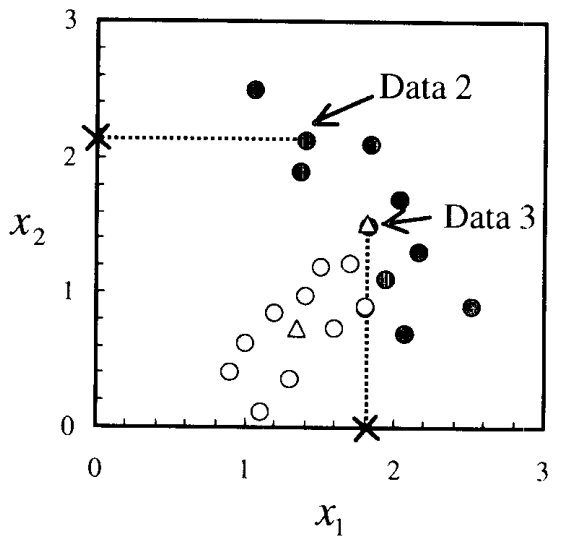

図 3 ：提案法による久測值の推定結果 $\left(x_{1}-x_{2}\right)$

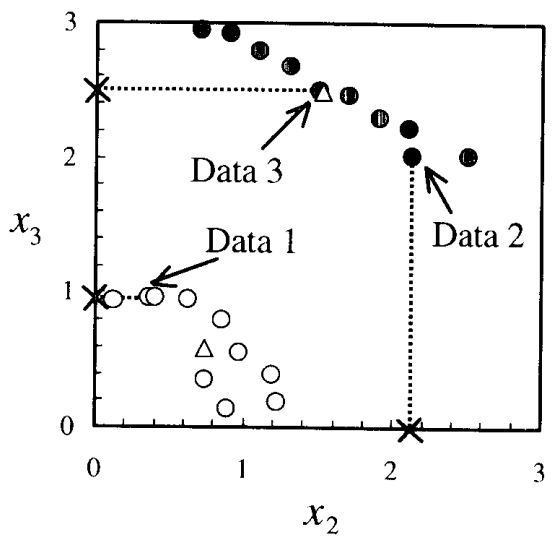

図 4：提案法による久测値の推定結果 $\left(x_{2}-x_{3}\right)$

法によって推定されたデー夕点である。四 3，四 4 よ ク，データの部分構造を考虑した，要当な久测值の推 定が行われていることがわかる。

\section{5. おわりに}

本研究では,ニューラルネットアプローチを用いて， デー夕の部分構造を考慮した局所的マイナー成分の抽 出法を提案した。また, 抽出されたマイナ一成分を解 いる久测值の推定方法も提案した。提案法を，インフ オメーションフィルタリングなどの実用アプリケーシ ヨンに適朋することが，今後の課題である。

\section{参 考 文 献}

[1] E. Oja: A simplified neuron model as a principal component analyzer, Joumal of Mathematical Biology, Vol.15, pp.267-273 (1982)

[2] E. Oja: Principal components, minor components, and linear neural networks, Neural Networks, Vol.5, pp.927-935 (1992)

［3］宫本定明：クラスタ一分析入門，森北出版 (1999)

[4]本多克丢，杉浦伸和，市橋秀友，荒林昭一，九津兒 洋：最小 2 乗基準を用いた Fuzzy $c$-Varieties 法に 扮ける久測值の処理法, 日本ファジィ学会誌, Vol. 
13. No.6, pp.132-140 (2001)

[5] J. C. Bezdek, C. Coray, R. Gunderson and J. Watson: Detection and characterization of cluster substructure. II. fuzzy $c$-varieties and convex combinations thereof, SIAM Journal on Applied Mathematics, Vol.40, No.2, pp.358-372 (1981)

(2002年 8 月 1 日 受付)

(2002年 11 月 16 日 採録)
[問い合わせ先]

干581-8511 大阪府八尾市楽音寺:6-10

大阪経済法科大学教養部

只志賢

TEL : 0729-41-8211

FAX : 0729-41-4145

E-mail : ch_oh@keiho-u.ac.jp

\section{抧 志督 [i]:会员]}

2002年大阪府立大学大学院工学研究科 博士後期課程䉓気 - 情報系尃攻修了. 同 年大阪経済法科大学教養部講師となり, 現在に至る。灭学博士。ファジィクラス タリング、データマイニングの研究に従 事。日本ファジィ学会, システム制御情 報学会，電子情報通信学会，IEEEの会 真.

\section{市橋 秀友 [正会覚]}

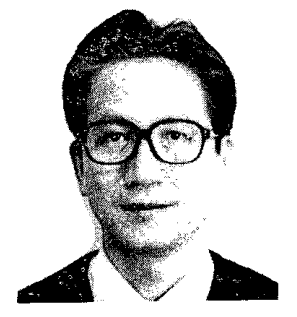

1971年大阪府立大学:工学部経営工学科 卒業. 同年松下電器應業侏入社, 1981年 大阪府立大学二学部経営工学科助手, 1987年同講師，1989年同助教授，1993年 同教授となり，現在に至る。厂学博士。 ファジィ理論や二ューラルネットワーク などでのデー夕解析法の知的システムや 人間機械システムへの灾用研究に従事. IEEE, 日本ファジィ学会, システム制御 情報学会, 電子情報通信学全, 日本経営 工学会などの会員。
告笨㽞克宏

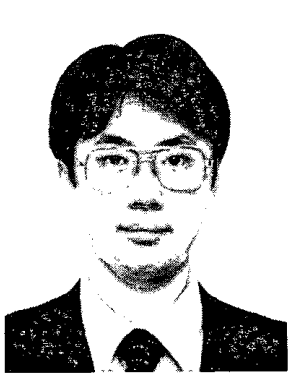

1999年 3 月大服府立大学院工学研究科 博士:前期課程電気 - 情報系専攻修了。同 年. 4 月日本電信電話株入社。同年10月大 阪府立大学:【学部助手となり現在に至る. ニューラルネットワーク, ファジィクラ スタリングの研究に従事. 日本経営工学 会, 日本ファジィ学会の会員.

\title{
Extraction of Local Minor Component by Fuzzy Clustering and Missing Value Estimation
}

\author{
by
}

\section{Chi-Hyon OH, Katsuhiro HONDA, Hidetomo ICHIHASHI}

\section{Abstract :}

In this paper, a method of extracting local minor components, that takes memberships to cluster into account, is presented. A simple neural PCA approach is employed to extract the components. The components well represent the distinctive structures of the data set. The way of estimating missing values by using the local minor components is also introduced.

Keywords : minor component, fuzzy clustering, neural PCA approach, missing value estimation

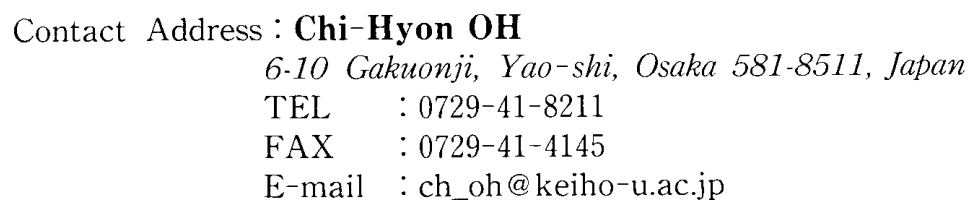

